\title{
A Simbologia de Marielle Franco nas guerras culturais do Brasil polarizado: uma análise discursiva
}

\author{
Marielle Franco's Symbology in the cultural wars of a polarized Brazil: a \\ discursive analysis
}

\section{Priscila Muniz de Medeiros}

Professora do curso de Jornalismo e do Programa de Pós-Graduação em Ciência da Informação da Universidade Federal de Alagoas (Ufal). Doutora em Comunicação pela Universidade Federal de Pernambuco (UFPE)

\section{Natália Martins Flores}

Jornalista, doutora em Comunicação pela Universidade Federal de Pernambuco (UFPE) e pesquisadora colaboradora do Laboratório de Estudos Avançados em Jornalismo (Labjor) da Universidade Estadual de Campinas (Unicamp).

\section{RESUMO}

0 assassinato de Marielle Franco ganhou centralidade nos debates políticos no Brasil a ponto de a vereadora ser alvo constante de campanhas desinformativas após sua morte. Neste artigo, exploramos a razão de Marielle ter se transformado em um símbolo que incomoda tanto determinado espectro político brasileiro, a partir da análise de discurso. Analisamos os movimentos interdiscursivos de um corpus composto por 38 discursos proferidos pela ex-vereadora na Câmara Legislativa do Rio de Janeiro entre os anos de 2017 e 2018 e 36 textos de notícias falsas divulgadas nas redes sociais após a sua morte. Além de entendermos que, para o campo discursivo rival, a imagem de Marielle se transformou em uma metonímia da própria esquerda, concluímos que, ao questionar o abuso e violência policial nas favelas, o discurso da vereadora tensionava o esquema discursivo binário do conservadorismo punitivo. A sua morte pelas mãos de ex-policiais era uma narrativa que, por ameaçar tal coerência discursiva, foi recontada através de fake news.

PALAVRAS-CHAVE: Desinformação; Polarização política; Marielle Franco; Análise de discurso; Guerras culturais.

\section{ABSTRACT}

The murder of Brazilian concilwoman Marielle Franco gained centrality in political debates in Brazil to the point that she became a constant target of disinformation campaigns after her death. Based on discourse analysis, we try in this paper to understand the reason why Marielle has become a symbol that disturbs a certain Brazilian political spectrum. We analyzed the interdiscursive movements of a corpus composed of 38 speeches given by the former councilor in the Legislative 
Chamber of Rio de Janeiro between 2017 and 2018 and 36 texts of fake news published on social networks after her death. In addition to understanding that, for the rival discursive field, Marielle's image became a metonymy of the left itself, we concluded that, by questioning the police violence in the favelas, the councilwoman's discourse tensioned the binary discursive scheme of punitive conservatism. Her death by the hands of former police officers was a narrative that, for threatening such discursive coherence, was rebuilt through fake news.

KEYWORDS: Misinformation; Political polarization; Marielle Franco; Discourse analysis; Culture wars

\section{RESUMEN}

El asesinato de Marielle Franco ganó protagonismo en los debates políticos en Brasil hasta el punto de que la consejera fue un blanco constante de campañas de desinformación tras su muerte. En este artículo exploramos la razón por la cual Marielle se ha convertido en un símbolo que molesta a cierto espectro político brasileño, a partir del análisis del discurso. Analizamos los movimientos interdiscursivos de un corpus compuesto por 38 discursos pronunciados por la exconsejera en la Cámara Legislativa de Río de Janeiro entre 2017 y 2018 y 36 textos de noticias falsas publicadas en redes sociales tras su muerte. Además de entender que, para el campo discursivo rival, la imagen de Marielle se convirtió en una metonimia de la propia izquierda, concluimos que, al cuestionar el abuso y la violencia policial en las favelas, el discurso de la concejala tensó el esquema discursivo binario del conservadurismo punitivo. Su muerte a manos de ex policías fue una narrativa que, por amenazar tal coherencia discursiva, fue recontada a través de fake news.

PALABRAS CLAVE: Desinformación; Polarización política; Marielle Franco; Análisis del habla; Guerras culturales

Submetido em 08 de Junho de 2021

Aceito em 21 de Setembro de 2021

\section{Introdução}

Em outubro de 2018, dois candidatos que disputavam as eleições pelo partido de extrema-direita PSL quebraram uma placa feita em homenagem à vereadora Marielle Franco (PSOL), assassinada no início daquele ano. Para uma porção da população brasileira, o ato foi visto como uma violência simbólica contra uma mulher negra vítima de um assassinato bárbaro. Uma outra parcela da 
população apoiou os candidatos, entendendo que a ação deles estaria "restaurando a ordem", nas palavras do agora senador Flávio Bolsonaro, já que a placa, fixada na praça Floriano, no Rio de Janeiro, estaria depredando o espaço público. Em março de 2021, uma placa semelhante foi inaugurada oficialmente em frente à Câmara dos Vereadores do Rio de Janeiro. Mesmo antes da homenagem oficial, a placa foi reproduzida em espaços públicos e privados no País inteiro, sendo, hoje, facilmente encontrada para comercialização como item decorativo em diferentes lojas online. A "guerra das placas" representa muito mais do que uma disputa sobre a legalidade da instalação de um artefato em um espaço físico. A placa ganhou uma dimensão simbólica porque o próprio nome Marielle Franco se tornou símbolo político e cultural.

Em maio de 2021, em meio à Comissão Parlamentar de Inquérito (CPI) que visava a investigar a atuação do Governo Federal na condução da pandemia de covid-19, um áudio em que a secretária de Gestão do Trabalho e da Educação do Ministério da Saúde, Mayra Pinheiro, fazia críticas à Fundação Oswaldo Cruz foi amplamente divulgado pela mídia. No áudio, ouvia-se que "tudo deles envolve LGBTI, eles têm um pênis na porta da Fiocruz. Todos os tapetes das portas são a figura do Che Guevara, as salas são figurinhas do Lula Livre, Marielle Vive". No discurso verbalizado por uma figura política abertamente ligada ao campo da direita, chama a atenção que o nome de Marielle apareça associado ao que é um dos maiores símbolo mundiais da esquerda comunista (a imagem de Che Guevara) e ao nome do mais conhecido líder esquerdista da história do Brasil (o expresidente Luís Inácio Lula da Silva).

Marielle Franco e o motorista do carro onde estava, Anderson Gomes, foram assassinados no dia 14 de março de 2018, no bairro do Estácio, na região central do Rio de Janeiro. Desde o início das investigações, a principal hipótese da polícia era a de que se tratou de um crime com motivações políticas. A participação de exPoliciais Militares e integrantes de milícias foi cogitada desde o início, e em 10 de março de 2020, a Justiça do Rio de Janeiro determinou que o Policial Militar reformado Ronnie Lessa e o ex-Policial Militar Élcio Vieira de Queiroz fossem 
julgados por júri popular pelas mortes. Eles teriam sido os executores, mas, até junho de 2021, as investigações ainda não haviam concluído quem teria sido o mandante.

A importância discursiva de Marielle Franco foi evidenciada logo após a sua morte, quando grupos de extrema-direita começaram a promover intensas campanhas desinformativas e difamatórias contra a ex-vereadora. Um primeiro questionamento seria a função discursiva de tais campanhas, já que Marielle não poderia disputar mais nenhuma campanha política, portanto, não seria uma adversária a ser vencida. 0 que levou Marielle Franco, que, à época da sua morte, ocupava um cargo legislativo em nível municipal, a ganhar tamanha centralidade nos debates políticos do Brasil? Especificamente, porque o símbolo Marielle Franco incomoda tanto determinado espectro político brasileiro a ponto de ela, mesmo após a sua morte, ter sido vítima de uma pesada campanha desinformativa? Por que discursos memoriais como a placa ou a inscrição "Marielle vive" são compreendidos como ameaças pela extrema-direita brasileira? A nossa pesquisa teve o objetivo de jogar luz sobre esses questionamentos através de uma análise discursiva de dois conjuntos de materialidades textuais distintos: as transcrições dos 38 discursos proferidos pela ex-vereadora na Câmara Legislativa do Rio de Janeiro entre os anos de 2017 e 2018 e os conteúdos desinformativos que circularam sobre Marielle Franco nos meses que seguiram a sua morte.

Por conteúdos desinformativos, nós entendemos informações falsas que são deliberadamente compartilhadas para prejudicar alguém ou algum grupo (Wardle; Derakshan, 2017). Trata-se de um tipo específico de enunciados que compõem um fenômeno ainda maior, que vem sendo chamado de desordem informacional. Os conteúdos desinformativos são, hoje, comumente chamados de fake news, apesar de o termo ser rechaçado por alguns autores. Berger (2018) defende que o uso da expressão ajuda a minar a credibilidade de informações que realmente atendem aos padrões de qualidade, uma vez que "notícia" significaria informação verificável de interesse público, e aqueles conteúdos que não compartilham desses princípios não mereceriam o rótulo de "notícias", mesmo se acompanhados pelo termo 
"falsas". Wardle e Derakshan (2017) também se abstêm de usar fake news porque consideram a expressão "lamentavelmente inadequada para descrever os fenômenos complexos de poluição da informação" (p.5, tradução nossa).

\section{Polarização política e os novos ecossistemas midiáticos}

Nos últimos anos, mudanças nos ecossistemas midiáticos foram determinantes na promoção de significativas transformações políticas e sociais ao redor do globo. Estudiosos começaram a voltar sua atenção para a relação entre uma maior participação popular nos debates políticos proporcionada pelas mídias digitais e o aumento da polarização política. Além disso, também começaram a ser observadas relações entre esse engajamento digital dos cidadãos na política com o surgimento de uma nova relação das pessoas com os eventos políticos, que passou a ser definida por um viés muito mais emocional e menos racional. Tal fenômeno estaria na base do já bastante utilizado conceito de pós-verdade.

Apesar de já ser amplamente difundido, especialmente nos meios acadêmicos, o termo pós-verdade é relativamente novo. Em 2016, foi escolhido como "palavra do ano" pelo dicionário Oxford de Língua Inglesa, que a definiu como "relativo ou referente a circunstâncias nas quais os fatos objetivos são menos influentes na formação da opinião pública do que as emoções e as crenças pessoais". McIntyre (2018) defende que, mesmo que falseamentos não sejam novidades, a ideia de que os fatos são menos importantes do que os sentimentos na formação de nossas crenças sobre questões empíricas parecem ser. "O mais impressionante sobre a ideia de pós-verdade não é apenas o fato de a verdade estar sendo desafiada, mas que ela está sendo desafiada como um mecanismo de afirmação de dominação política" (Mcintyre, 2018, prefácio, para. 4, tradução nossa).

O novo patamar que as emoções e as crenças pessoais ganharam no debate político está intrinsecamente associado às mudanças nos ecossistemas de mídia mencionadas anteriormente. Em uma sociedade dominada pelo modelo de 
comunicação de massa, ainda que existissem cidadãos ativistas e militantes, a maioria da população simplesmente acompanhava os fatos políticos através da mediação dos veículos de comunicação. A maior parte dos cidadãos desempenhava o papel de espectadores passivos que, a cada dois anos, escolhiam os candidatos com base em suas crenças pessoais e influenciados em maior ou menor grau pelos discursos hegemônicos e pouco diversificados oriundos da mídia de massa. Havia menos implicação pessoal e emocional no processo. Com as mídias digitais e a liberação do polo de emissão das mensagens que elas possibilitaram (Lemos, 2009), os cidadãos passaram a se engajar mais com o discurso político, tornandose seus produtores e seus divulgadores. Dessa forma, surgiram mais militantes ativos e um debate político muito mais caracterizado pelo mencionado viés emocional (Mason, 2016), já que um maior envolvimento ativo com a política está associado frequentemente à construção de uma identidade, de uma persona pública, o que acaba fomentando o aparecimento de paixões. Implicados na defesa de um partido ou de um político, os usuários das mídias sociais acabaram por se colocar num lugar análogo ao do torcedor de futebol. A paixão é o que liga o torcedor a seu time, e não um raciocínio lógico sobre quantidades de títulos ou estrutura organizacional.

Tal cenário está intrinsecamente ligado ao aumento nos processos de polarização política no mundo inteiro. A polarização do debate político pode ser entendida como a redução da diversidade política a apenas dois polos, num processo de alinhamento discursivo (Ortellado; Ribeiro, 2018). Esse não é um fenômeno novo. Nos EUA, as eleições presidenciais são historicamente disputadas entre Republicanos e Democratas. No Brasil, PSDB e PT protagonizaram a maior parte das disputas presidenciais desde a redemocratização, tendo o PSDB perdido espaço para a extrema-direita nas eleições de 2018, fato que consolidou um processo de polarização assimétrica da sociedade brasileira, que assistiu o partidarismo de direita se radicalizar.

Se a polarização política sempre existiu, o que mudou foi justamente o forte viés emocional dessa polarização. Abranches (2019) define o fenômeno como uma 
polarização radicalizada. Iyengar e colegas (2019) defendem que a tradicional polarização ideológica, baseada nas diferenças entre posições políticas, está agora dividindo espaço com uma outra forma de polarização: a polarização afetiva. A polarização afetiva é um fenômeno de animosidade entre defensores de diferentes partidos em que ambos os grupos têm dificuldades de socializar com o lado oposto, desconfiando de seus defensores e nutrindo sentimentos ruins em relação a eles.

Um fenômeno que, segundo os autores, está nas raízes da polarização afetiva é o alinhamento das identidades partidárias e ideológicas e sua convergência com outras identidades sociais salientes, como raça e religião:

Este declínio do corte transversal de identidades está na raiz da polarização afetiva, de acordo com Mason (2015, 2018b). Ela mostrou que aqueles com identidades partidárias e ideológicas consistentes se tornaram mais hostis para com os de fora do partido sem necessariamente mudar suas posições ideológicas, e aqueles que alinharam identidades religiosas, raciais e partidárias reagem mais emocionalmente às informações que ameaçam suas identidades partidárias ou posturas sobre diferentes questões. Em essência, a classificação tornou muito mais fácil para os partidários fazerem inferências generalizadas sobre o lado oposto, mesmo que essas inferências sejam imprecisas (Iyengar et al. 2019).

No Brasil, o alinhamento das identidades sociais e políticas colocou em oposição duas diferentes formações discursivas (FDs): a conservadora e a progressista. O conflito entre elas mistura discursos políticos e morais. Na introdução do presente artigo, a transcrição da fala da secretária de Gestão do Trabalho e da Educação do Ministério da Saúde, Mayra Pinheiro, além de listar Marielle Franco em meio a nomes emblemáticos da esquerda brasileira e mundial, também opera uma outra construção de sentidos: ela associa os nomes de esquerda à causa LGBTQIA+ e mesmo à alegada existência de um órgão genital masculino inflável na porta da Fundação Oswaldo Cruz. Fica claro que a esquerda está, nesse discurso, compreendida a partir de uma generalização que associa elementos políticos e morais.

Gallego e colegas (2017) afirmam que a relação entre discursos políticos e morais não é nova no Brasil, mas eles acreditam que, no passado recente, o 
discurso moral era instrumentalizado pelo discurso político. Atualmente, o contrário parece estar acontecendo. Para os autores, a anterior polarização entre uma direita liberal que defende a meritocracia baseada no livre empreendimento e uma esquerda que defende intervencionismo político para a promoção de justiça social não foi substituída, mas passou a ser subordinada a um novo antagonismo entre um conservadorismo punitivo e um progressismo compreensivo. Ambas as formações discursivas serão detalhadas mais à frente.

Uma outra transformação importante nos ecossistemas midiáticos também pode estar ligada ao processo de polarização radicalizada. Alguns teóricos vêm alegando que a fragmentação das fontes noticiosas ocasionada pela liberação do polo de emissão (Lemos, 2009) e o consequente crescimento de veículos hiperpartidários, associados aos algoritmos de recomendação e relevância que sugerem conteúdo aos usuários das redes sociais digitais levou os cidadãos a viverem em bolhas ideológicas (Parisier, 2011; El-Bermawy, 2016; Lee, 2016). É importante salientar que não há consenso científico acerca da existência, da real importância ou das consequências políticas das bolhas ideológicas ou "câmaras de eco". Estudos têm sido feitos no intuito de analisar até que ponto a exposição a diferentes opiniões e conteúdos nas mídias digitais variam entre indivíduos de posições políticas distintas. Enquanto nos Estados Unidos uma pesquisa mostrou uma quantidade substancial de sobreposição nas distribuições ideológicas das contas do Twitter seguidas por usuários em extremos opostos do espectro político (Eady et al, 2019), no Brasil outra pesquisa mostrou a existência de clusters de informações nas conversas do Twitter sobre fatos políticos polêmicos no país (Recuero et al, 2017). A pesquisa brasileira concluiu que existem processos de filtragem que fazem os nós de cada grupo político darem visibilidade apenas às informações que se combinam com suas posições políticas. Obviamente, resultados tão diferentes podem ser devidos a questões metodológicas, mas não podemos descartar a possibilidade de influência de particularidades regionais.

Em um contexto social de hiperpolarização, no qual a polarização ideológica convive com uma polarização afetiva, no qual as personas públicas são construídas 
a partir de identidades políticas cada vez mais alinhadas a identidades sociais e no qual as crenças pessoais e emoções se tornaram mais relevantes do que os fatos objetivos na construção da opinião pública, conteúdos desinformativos têm um potencial enorme de circularem e reverberarem na esfera pública, ficando, muitas vezes, blindados em relação a checagens e desmentidos. Na hipótese de as câmaras de eco estarem realmente operantes e influentes, o próprio acesso às checagens pode não ocorrer amplamente. Ou seja: se um grupo de cidadãos tem acesso a informações que contemplam apenas um polo da disputa política, incluindo fake news, seus membros serão menos propensos a ser confrontados com versões diferentes dos fatos. E mesmo quando tiverem acesso a elas, emoções e paixões despertadas pelo fenômeno da polarização afetarão sua tendência a acreditar nos desmentidos. Há ainda o reforço do "viés de confirmação" (Bakir; Mcstay, 2017), uma tendência que as pessoas têm de validarem apenas as informações que confirmam suas crenças pré-existentes.

$\mathrm{Na}$ era da pós-verdade, as instituições que comumente atuaram como portadoras da verdade, como a ciência e o jornalismo, passam por uma relevante crise de legitimidade, num processo que muitos vêm chamando de crise epistêmica. Se a realidade era relativamente consensual na era das mídias de massa, com variações sobre como as pessoas a interpretavam, na era das mídias pós-massivas tal consenso se foi: grupos distintos vivem sob o manto de diferentes realidades. Podemos interpretar a era das mídias pós-massivas a partir de uma perspectiva foucauldiana, enquanto um contexto no qual a própria natureza do funcionamento discursivo vem à tona. Os fenômenos sociais ligados à pós-verdade, ao viés de confirmação e à relação cada vez mais emocional e menos racional dos indivíduos com os fatos expõem como os discursos constroem regimes de verdade específicos para grupos e sociedades em determinados períodos históricos e contextos sociais. Sujeitos e objetos discursivos, ou seja, quem somos e do que falamos, só existem em relação a um dado regime de verdade, a uma formação discursiva específica que estabelece um par de regras para os enunciados (Foucault, 1971). Esse funcionamento pode nos ajudar a explicar a forma como 
identidades e perspectivas de mundo distintas são formadas no espectro político e social.

\section{Materiais e métodos}

Nosso procedimento metodológico consistiu na análise dos movimentos interdiscursivos apresentados por um corpus dividido em dois conjuntos de materialidades discursivas: as transcrições dos 38 discursos proferidos pela exvereadora na Câmara Legislativa do Rio de Janeiro entre os anos de 2017 e 2018 e os conteúdos desinformativos que circularam nas redes sociais sobre Marielle Franco nos meses que seguiram a sua morte. No caso do primeiro conjunto textual, as transcrições foram coletadas no site da Câmara Municipal do Rio de Janeiro. Foram selecionados apenas os textos referentes às participações de Marielle Franco no órgão legislativo que apresentavam o título "discurso".

No caso do segundo conjunto textual, foram selecionados textos dispersos sobre a morte de Marielle Franco. Esse corpus foi constituído por notícias falsas divulgadas nas redes sociais sobre Marielle Franco em forma de textos e imagens. A coleta desses dados foi feita por meio do acesso às páginas de fact-checking: $a$. Boatos.org, $b$. E-farsas e $c$. Aos Fatos utilizando a palavra-chave "Marielle Franco" nos mecanismos de pesquisa dos sites. Focamos o conteúdo publicado no período de março de 2018 a março de 2019. A busca resultou em 36 textos (18 de Boatos.org, 5 de E-farsas e 13 de Aos Fatos). 0 confronto com esses textos nos permitiu mapear as formações discursivas predominantes na materialidade analisada.

A noção de formação discursiva (FD) nos dá alguns direcionamentos interessantes para o desdobramento das relações entre o material linguístico e o contexto social. Ela foi criada por Foucault (1969; 1971) para evidenciar a dispersão de um discurso em determinado período histórico e ganhou formas diversas na Análise de Discurso, dependendo da abordagem teórica adotada (Maingueneau, 2011). Na categorização de Maingueneau (2011), a noção é 
utilizada como uma unidade não temática definida a partir da interpretação do analista, diferindo de elementos pré-formatados de unidades temáticas, que estão explicitamente no texto, como gêneros discursivos e marcas linguísticas.

Para Maingueneau (2011), a formação discursiva é um elemento central da Análise de Discurso, pois permite a transgressão das fronteiras das marcas textuais, numa relação permanente entre "dentro" e "fora", ou seja, discurso e interdiscurso. A FD encontra ressonância, portanto, no conceito de interdiscurso ao mostrar que todos os discursos se constituem na heterogeneidade, carregando elementos e fragmentos de discursos que lhe são opostos (Maingueneau, 2008).

\section{As guerras culturais em sua dimensão discursiva}

Como mencionado anteriormente, Gallego e colegas (2017) distinguiram duas posições políticas centrais no Brasil contemporâneo: o conservadorismo punitivo e o progressismo compreensivo, e que serão, no presente artigo, tratados a partir do conceito de formações discursivas. Através de questionários aplicados para militantes de ambos os lados, os autores buscaram medir o impacto das guerras culturais em ambos os grupos. Eles verificaram que as principais pautas que uniam os militantes conservadores entrevistados era o discurso punitivo (82.6\% apoiavam o aumento de pena para punir criminosos, $84.6 \%$ apoiavam a redução da maioridade penal) e a rejeição aos programas sociais e de redistribuição de renda (82.2\% pensavam que o programa Bolsa Família estimula as pessoas a não trabalhar e $75.2 \%$ pensavam que as cotas não são uma boa medida). Questões relativas ao papel da religião, direito da mulher ou direitos LGBTQIA+ apresentaram maior variabilidade entre as respostas. Já os manifestantes do lado progressista "apresentam um perfil muito coeso, tendo um grande número de entrevistados que respondeu o questionário exatamente da mesma maneira" (Gallego et al., 2017, p. 40).

Os manifestantes que se identificam como progressistas ou de esquerda têm um padrão muito coeso de posições sobre questões morais referentes 
a mulheres, LGBT, drogas, população negra ou políticas de mobilidade social. Uma grande homogeneidade nas respostas caracteriza este grupo. Os manifestantes que se definem como conservadores ou de direita, porém, não apresentam esse grau de homogeneidade como grupo, com uma disparidade muito maior nas respostas referentes a questões morais. As caraterísticas comuns são o punitivismo, a rejeição às políticas públicas de mobilidade social e, fundamentalmente, o antipetismo, que é o fator que oferece maior coerência interna e identidade ao grupo (Gallego et al., 2017, p. 44).

Antes de expor o resultado da nossa análise sobre os principais temas tratados por Marielle Franco em seus discursos oficiais na Câmara dos Vereadores do Rio de Janeiro, cabe uma contextualização da atuação da parlamentar. Durante o seu mandato, Marielle presidiu a Comissão de Defesa da Mulher, além de integrar uma comissão que tinha o objetivo de monitorar uma intervenção federal em favelas do Rio de Janeiro. Além disso, Marielle recorria constantemente a marcas discursivas que reforçavam a sua identidade de mulher, negra, bissexual e moradora do Complexo da Maré (comunidade carioca). Sua atuação, bem como suas marcas identitárias, tiveram bastante presentes em seus discursos oficiais.

Tabela 1: temas mais frequentes nas transcrições dos discursos de Marielle Franco na Câmara Municipal do Rio de Janeiro

\begin{tabular}{|c|c|}
\hline Segurança pública & 24 \\
\hline Questões de gênero & 21 \\
\hline Questões raciais & 16 \\
\hline $\begin{array}{l}\text { Questões relativas à comunidade } \\
\text { LGBTQIA+ }\end{array}$ & 8 \\
\hline Educação & 6 \\
\hline Saúde & 6 \\
\hline Intolerância religiosa & 3 \\
\hline
\end{tabular}

Fonte: produzida pelas autoras

O tema mais presente nas 38 transcrições analisadas foi o da segurança pública, que apareceu 24 vezes. Como mostrou a pesquisa de Gallego et al. (2017), 
esse é justamente a pauta que mais une manifestantes conservadores, que abordam a questão a partir de uma lógica punitiva.

Na maior parte das vezes (18 das 24) havia, no discurso de Marielle, uma clara crítica à violência policial nas favelas cariocas. Além disso, o tema da segurança pública estava constantemente associado ao dos direitos dos moradores das favelas. Um enunciado que aparece em diferentes discursos da ex-vereadora é “a favela não é um problema de polícia; a favela é um problema de política”. Os extratos abaixo são exemplos da abordagem dada por Marielle ao tema:

Extrato 1: Este pronunciamento de hoje é fundamentalmente para pensarmos: que direito é esse de ir e vir do favelado e da favelada, a ser garantido ou não pelo próprio Estado? Quando essas operações acontecem, escolas e postos de saúde fecham. Nós recebemos fotos - como não foi diretamente da minha equipe, hoje não projetei para que as senhoras e os senhores acompanhem -, de cápsulas de bala que enchem um saco plástico em um dia de operação. Havia crianças e profissionais no posto da Vila do João deitados no chão (discurso proferido em 23/03/2017).

Extrato 2: E aí defensores da ação policial falam aí que: "De repente, estava com 13 anos na porta do baile ou na feira". Não, essa criança estava dentro da escola. Essa criança estava na aula de Educação Física, algo que, para ela, era importante e significava um futuro melhor. Aí eu pergunto às senhoras e aos senhores, como o professor dela perguntou: "Eu inclui e estimulei o direito da Maria Eduarda de sonhar; e quem tirou esse direito?". É mais uma vida perdida, assim como da Hosana. Nós não podemos nos furtar desse debate (discurso proferido em 04/04/2017).

Extrato 3: E essas crianças que já ficam diversos dias sem aulas... No ano passado tiveram 25 dias a menos de ano letivo. Quero ver, depois, algum vereador ou vereadora ou alguém vir dizer que é meritocrático, que não estuda porque não quer, não estuda porque não está muito a fim! Porque, na verdade, ele é favelado, ele é negro, ela é favelada, ela quer ser mulher de bandido, ou ela está a fim de viver com a mamata do bolsa família! Porque é isso que falam (discurso proferido em 20/06/2017).

Os enunciados presentes nos extratos 1, 2 e 3 mostram como a parlamentar associava, num mesmo discurso, temas diversos e complexos, como a violência policial, a educação, a saúde e o racismo. Nos extratos 2 e 3, há um movimento interdiscursivo (Maingueneau, 2008) que tenta explicitar, com o intuito de invalidar, o que seria o discurso do outro lado. Além do uso de "meritocracia", 
léxico central na formação discursiva da direita liberal, há sugestões de que o outro lado teria posturas racistas e machistas.

Além de ser o principal tema levantado por Marielle Franco em seus discursos, a questão da violência urbana e segurança pública foi central nas disputas discursivas sobre a sua morte. Em 2017, o Brasil apresentava uma taxa de 31,6 homicídios por 100 mil habitantes, a maior taxa de homicídios de sua história (Cerqueira et, al., 2019). Essa realidade transformou a violência em tema recorrente de conversa para os brasileiros, principalmente em um cenário préeleitoral. Assim, a violência urbana passou a ser um dos principais assuntos das eleições presidenciais de 2018, junto à corrupção.

As falsas narrativas sobre Marielle Franco surgiram nas redes sociais rapidamente após seu assassinato, em março de 2018. Os rumores se espalharam no Twitter e acabaram chegando ao WhatsApp entre a noite de 15 de março e a tarde de 16 de março. A narrativa principal afirmou que a vereadora estaria vinculada a grupos do narcotráfico do Rio de Janeiro e que atuava na defesa deles. Supostas fotos da Marielle com o líder do narcotráfico Marcinho VP foram espalhadas no WhatsApp, afirmando que eles já haviam sido casados.

Os boatos começam a ganhar maior repercussão quando atores políticos passam a divulgar esse conteúdo. 0 deputado de direita Alberto Fraga e a juíza Marília Castro Neves foram os principais divulgadores desse conteúdo desinformativo, em suas páginas pessoais no Facebook (Mendonça, Marreiro, 2018). Veículos hiperpartidários de direita também desempenharam um papel importante na disseminação de conteúdos desinformativos sobre Marielle. Um mapeamento de dados feito pelo projeto Monitor do Debate Político no Meio Digital (2018) rastreou um total de sete notícias do caso divulgadas nas redes sociais. Entre eles, um texto publicado pelo veículo hiperpartidário de direita Ceticismo Político foi o mais compartilhado, com 232 mil compartilhamentos no primeiro dia. 0 texto deu destaque às declarações da juíza Marília Castro, mas sem se preocupar em revelar que se tratavam de alegações falsas. 
Para compreendermos as condições de possibilidade dos discursos que integraram as fake news sobre Marielle Franco, há um elemento central, que é apontado por Alonso (2019) em sua descrição da comunidade moral bolsonarista, que "se estrutura na crença compartilhada em códigos binários, que divide o mundo em bem e mal, sagrado e profano, gente de família e indecentes, cidadãos de bem e bandidos, éticos e corruptos, nacionalistas e globalistas" (p, 52). Para a autora, esse maniqueísmo reduz a complexidade da realidade a estereótipos administráveis, ativando sentimentos como afeto, medo e ódio, o que se alinha ao já descrito fenômeno da polarização afetiva.

Marielle Franco era considerada uma defensora dos direitos humanos. Frequentemente, a formação discursiva do conservadorismo punitivo "produz um efeito de sentido de desconstrução da finalidade da atuação dos grupos de defesa dos Direitos Humanos, associando suas práticas à defesa de bandidos" (Souza, 2017, p. 1). Tal aspecto do conservadorismo punitivo simplifica o problema da criminalidade a uma fórmula superficial em que os criminosos detêm o papel de vilãos e os policiais detêm o papel de heróis. Esse processo de simplificação é característico da gênese do discurso, que constrói um simulacro do seu outro para não perder sua identidade discursiva (Maingueneau, 2008). Os enunciados do outro são, a partir daí, compreendidos a partir de uma rede semântica específica do intérprete e desse negativo do seu próprio discurso (Maingueneau, 2008).

Uma vez que, para o conservadorismo punitivo, os defensores dos direitos humanos defendem bandidos e os policiais são heróis, a morte de Marielle pelas mãos de policiais criminosos (o que foi levantado como principal hipótese desde o início das investigações do assassinato) não seria uma narrativa que se encaixaria em tal sistema de crenças. No extrato a seguir, está presente um dos primeiros conteúdos desinformativos que circulou no WhatsApp após a morte de Marielle:

Extrato 4: SERÁ VERDADE? QUEM ERA MARIELLE -Engravidou aos 16 anos. -Ex-Mulher de Marcinho VP. -Usuária de maconha. -Eleita pelo comandovermelho. -Foi defender faccao [sic] rival no bairro do Acari no RJ. -Exonerou 6 funcionários recentemente. Mas quem a matou foi a Polícia!!! (Boatos.org, E-farsas, Aos Fatos).

Dossiê Guerras Culturais - https://revistaecopos.eco.ufrj.br/

ISSN 2175-8689-v. 23, n. 3, 2020

DOI: 10.29146/ecopos.v24i2.27694 
A última frase é enunciada como ironia, uma vez que o texto tenta construir a ideia de que Marielle Franco era envolvida com traficantes de drogas e grupos criminosos e que tais conexões teriam provocado a sua morte, não a polícia. As menções à organização criminosa Comando Vermelho e ao traficante Marcinho VP são centrais nessa estratégia discursiva. De acordo com o site Boatos.org, uma outra mensagem falsa semelhante que circulou acrescentava que Marielle Franco era filha do famoso traficante de drogas Fernandinho Beira-Mar, que teria financiado sua campanha. Uma terceira mensagem compartilhada num vídeo postado nas redes sociais seguiu a mesma linha, afirmando que o Comando Vermelho teria financiado sua campanha eleitoral:

Extrato 5: E ela foi eleita pelo Comando Vermelho. A favela bancou ela. 0 tráfico, o tráfico bancou ela, o tráfico colocou ela lá dentro. (Boatos.org, Efarsas, Aos Fatos).

No interior da formação discursiva do conservadorismo punitivo, policiais criminosos são um paradoxo impossível. A campanha desinformativa foi pensada com o intuito de adequar os fatos a uma narrativa que coubesse no dizível da FD. As fake news tiveram, então, a função de convencer as pessoas de que Marielle teria sido assassinada não por milícias, mas por traficantes de drogas. Os mesmos bandidos que, como defensora dos direitos humanos, ela costumava defender. Para "provar" que Marielle Franco costumava defender bandidos, outro conteúdo desinformativo começou a circular nas redes:

Extrato 6: ACREDITEM SE QUISER !!! Hoje foi aprovado um projeto de lei da tal Marielle que reserva $20 \%$ das vagas em concursos públicos para menores infratores na cidade do Rio de Janeiro. É isso mesmo que vcs leram. Daqui a pouco vai ser vantagem ser menor infrator. CRIVELLA , VÊ SE TU VETA ESSA INDECÊNCIA !!! (Boatos.org).

A existência de um projeto de lei proposto por Marielle que daria privilégios a menores infratores, incentivando, assim, o crime, daria força ao discurso que acusa os defensores de direitos humanos de defenderem bandidos, ajudando a 
deixar intactos os códigos binários que sustentam a FD do conservadorismo punitivo. Os extratos a seguir são duas variações de chamadas para um vídeo no qual a ex-vereadora estaria defendendo "marginais". Esses conteúdos desinformativos tiveram o intuito de convencer as pessoas de que Marielle Franco defendia bandidos.

Extrato 7: Por favor, tirem 4 minutos para assistirem esse vídeo e tirem a conclusão sobre quem de fato era a vereadora Santa Marielle Franco. Vejam a atuação da Marielle, aos berros na Câmara defendendo marginais e dizendo que sua musa E a MC Carol, funkeira de umas letras bem porcas, por sinal. Assistam ao vídeo do vereador Carlos Jordy (Boatos.org).

Extrato 8: Vereadora assassinada protestava contra a morte de sete marginais mas ignorava as centenas de mortes de policiais e crianças inocentes causadas pelos "soldados" do tráfico, "vítimas da sociedade". Além disso ainda fez apologia de drogas e citou a "poesia" de uma "MC", que fazia sucesso com funks homofóbicos Mas isso ela ignorou. Vejam o vídeo e vomitem também (Boatos.org).

Páginas de fact-checking mostraram que não era Marielle Franco que aparecia no vídeo em questão, mas sim Talíria Petrone, à época vereadora pelo município de Niterói. O vídeo, bastante editado, mostra uma mulher negra reclamando da violência policial que resultou na morte de sete pessoas negras na favela do Salgueiro. Ainda é possível escutar a voz da oradora quando a imagem é substituída por um texto que afirma que as pessoas mortas eram criminosas.

Na nossa análise dos discursos oficiais de Marielle Franco, ficou evidenciado que o tema da violência policial nas favelas cariocas era um dos mais recorrentes em seus pronunciamentos. Em seu estudo, Souza (2017) argumenta que a FD conservadora estigmatiza os moradores das favelas, bem como suas manifestações culturais. A estigmatização carrega também um forte aspecto racial, uma vez que pessoas negras são lidas, de forma generalista, como criminosas. Nos extratos transcritos anteriormente, algumas marcas discursivas compartilham de tais valores. No extrato 5, por exemplo, lemos que "a favela bancou ela. 0 tráfico, o tráfico bancou ela, o tráfico colocou ela lá dentro". A favela é, aqui, enunciada como elemento associado ao tráfico. No estrato 7 , ter como musa uma cantora de funk é 
um elemento utilizado para desabonar a imagem de Marielle. Tais fragmentos indicam que o signo "favela", bem como outros associados a ele, como "funk" (expressão cultural periférica), assumem um sentido negativo em tais discursos. $\mathrm{Na}$ formação discursiva do conservadorismo punitivo, a favela e seus simbolismos são colocados do "lado mau" da disputa maniqueísta.

No extrato 8, os esquemas binários são reforçados pela alegação de que Marielle defendia marginais e ignorava policiais e crianças vitimadas pelo tráfico. Fica claro que o discurso propagado nos conteúdos desinformativos opera uma descomplexificação da realidade, que coloca de um lado os "marginais" e, do outro, a "população de bem", no extrato, representada por policiais e crianças vítimas dos traficantes. No discurso não há espaço, por exemplo, para as crianças moradoras da favela, que, no discurso de Marielle Franco (extratos 1, 2 e 3), eram elementos centrais, seja enquanto vítimas de balas perdidas nas operações policiais, seja por serem prejudicadas pelo fechamento das escolas nas mesmas operações. A vida dos agentes de segurança pública (policiais e guardas municipais) também apareceu como elemento nos pronunciamentos de Marielle em pelo menos seis ocasiões diferentes. No discurso de Marielle, a morte de civis moradores das favelas e de policiais faziam parte de uma mesma estratégia equivocada de combate ao crime, como demonstra o extrato 9, que fez parte do primeiro pronunciamento oficial de Marielle Franco na Câmara Municipal, ocorrido em 15 de fevereiro de 2017.

Extrato 9: Mas, também é necessário que haja uma preocupação com o trabalho de inteligência, com o trabalho de segurança, com o trabalho de antecipação, porque o resultado pode ser vitimar os policiais e vitimar os moradores de favela. 0 Complexo do Alemão tem denúncias diárias, tantos dos profissionais das UPP que ali estão, quanto dos seus moradores. A responsabilidade sobre esse tema do eixo da segurança e das violações precisa ser colocada preventivamente também nesta Casa, porque quem mais sofre são as mulheres faveladas que têm seus filhos vitimados ou presos (discurso proferido em 15/02/2017).

O discurso da ex-vereadora também demonstra incômodo com os esquemas binários que separavam discursivamente policiais e moradores da favela, e que, 
posteriormente, viriam a compor o elemento central dos conteúdos desinformativos que circularam após a sua morte.

Extrato 10: 0 que nos espantou, infelizmente, em uma audiência que foi convocada e organizada, foi o ponto de cisão. Para vocês terem uma ideia, fisicamente havia em um lado os profissionais da segurança pública e no outro os moradores. Como se o tema da segurança fosse algo que pudéssemos relacionar a uma dicotomia entre lado "B" e lado " $A$ ", entre bons e maus. Isso deixa rasteiro um debate que fala sobre vidas (discurso proferido em 26/04/2017).

O extrato 11 traz mais um conteúdo desinformativo que circulou no WhatsApp. A maior parte dos elementos discursivos discutidos estão presentes no texto (o binarismo entre policiais e criminosos, o entendimento dos direitos humanos como direitos de bandidos), mas, aqui, também pode ser verificado um forte aspecto racial nos enunciados:

Extrato 11: "Assassino foi descoberto! Não é PM, não é branco. É ligado ao TRÁFICO. A Mídia não fala mais de Marielle. Por que? Marielle foi morta por Thiago Macaco, negro, de origem pobre e bandido. Onde está o branco racista, policial e homofóbico que a esquerda e a Globo inventaram?" (Aos fatos, Boatos.org).

Com o intuito de manter a coerência discursiva da FD do conservadorismo punitivo, as notícias falsas sobre Marielle Franco também atuaram na desconstrução de argumentos centrais da FD rival, o progressismo compreensivo, a partir de um movimento interdiscursivo (Maingueneau, 2008). Trata-se de uma das formas do discurso de se constituir, a partir do outro que lhe opõe, sem deixar traços visíveis (Maingueneau, 2008). A existência de policiais racistas é enunciada como uma construção midiática, não como um fato. E a "prova" disso seria o fato de que o assassino de Marielle não teria sido um policial branco, mas um bandido, negro e de origem pobre. 0 ataque à mídia tradicional também está presente no enunciado, o que é indicial da crise epistêmica já mencionada no trabalho.

O esquema binário do cidadão de bem versus bandidos não é a única dualidade maniqueísta no discurso dos conteúdos desinformativos. No extrato 4 , a 
primeira informação sobre "quem era Marielle" diz que ela "engravidou aos 16 anos". A desinformação em questão tem como objetivo criar um julgamento moral sobre a ex-vereadora com base na crença compartilhada por certo grupo de que mulheres que engravidam ainda adolescente são indecentes. 0 arquétipo da mulher promíscua é mobilizado pelo discurso desinformativo a fim de construir uma imagem de Marielle que se opõe ao arquétipo de pureza e inocência das mulheres "de família". Há, também em tais discursos, um forte elemento racial. A sexualização e objetificação dos corpos de mulheres negras é um assunto amplamente discutido na literatura dos estudos interseccionais de gênero e raça.

A sexualização se refere à supervalorização dos seus traços físicos como textos que expressam estritamente e de maneira exacerbada o erotismo, a sensualidade e a sedução. Dessa maneira, tais sujeitos ocupam um lugar particular nas hierarquias de gênero e raça: aquele corpo fornecedor de prazeres carnais. Na contrapartida, as representações em torno das mulheres brancas são definidas - grosso modo - a partir de uma sexualidade ligada a códigos estéticos e comportamentais, oriundos da suposta moralidade inscrita na pele branca. Nesses termos, menos do que manifestação ou orientação sexual - como sugere sexualidade sexualização faz menção à situação particular vivenciada pelas negras nas Américas (Côrtes, 2005, p. 23-24).

Ainda no que diz respeito aos discursos de gênero, no extrato 7, Marielle é representada como uma mulher que "berra", marca discursiva que faz parte de uma tradição de opressão feminina que vem, historicamente, construindo a ideia de que mulheres com falas assertivas em posição de poder são "emocionalmente descontroladas", "histéricas", etc. Além disso, o extrato destaca que ela tem como musa uma funkeira de "letras porcas". Enquanto gênero musical, o funk é comumente estigmatizado em virtude do teor sexual de algumas canções.

O maior exemplo de conteúdo desinformativo que associa Marielle Franco à imagem de uma mulher promíscua é uma foto que começou a circular alguns dias após sua morte. A foto leva o binarismo em questão ao campo da visualidade. $\mathrm{Na}$ imagem, é possível identificar uma mulher vestindo pouca roupa e sentada no colo de um homem, que está ao lado de uma garrafa e um copo de cerveja. A imagem foi acompanhada do texto a seguir:

Dossiê Guerras Culturais - https://revistaecopos.eco.ufrj.br/

ISSN 2175-8689-v. 23, n. 3, 2020

DOI: 10.29146/ecopos.v24i2.27694 
Extrato 12: "Vereadora Marielle e Marcinho VP. Aí a santa marielle e seu marido na época, o traficante marcinho vp. É essa vadia que alguns alienados dementes, dizem que morreu porque seria presidente do Brasil. Não sem noção, essa piriguete morreu porque tinha envolvimento com bandidos" (Aos fatos).

Os elementos visuais na imagem evocam uma memória discursiva conservadora que estigmatiza mulheres que usam pouca roupa, prática que seria, junto ao ato de sentar-se no colo de um homem, incompatíveis com uma mulher de valores familiares. No texto que acompanha a imagem, elementos lexicais como "vadia" e "piriguete" reforçam a construção da imagem de promiscuidade que se tenta associar à ex-vereadora. As pessoas na imagem não são nem Marielle Franco, nem Marcinho VP. Páginas de fact-checking conseguiram rastrear a origem da fotografia, que foi inicialmente publicada numa página de Fotolog intitulada KTAPUTAS. Na legenda, constava a informação de que a foto foi tirada "no cabaré de jaqueline em pau dos ferros". A origem da imagem reforça a suspeita de que a mesma não foi uma imagem de um casal qualquer escolhida aleatoriamente. Muito provavelmente, ela foi cuidadosamente escolhida para criar o efeito de sentido desejado, preservando, assim, a integridade da formação discursiva do conservadorismo punitivo.

\section{Considerações finais}

A existência da ex-vereadora Marielle Franco enquanto ente político era, por si só, simbólica, uma vez seu corpo interseccionalizava uma série de marcadores sociais: uma mulher, negra e bissexual. Como verificamos na análise de seus pronunciamentos oficiais na Câmara Municipal do Rio, questões relativas a gênero, raça e sexualidade estavam entre os temas mais recorrentes em suas falas. Da mesma forma, como mostramos em nossa análise, elementos ligados ao gênero e à raça de Marielle Franco, bem como a sua origem periférica, foram utilizados de forma recorrente no discurso dos conteúdos desinformativos que circularam após a sua morte com o intuito de negativar a sua imagem. 0 fato de Marielle acumular 
tantas marcas identitárias que se tornaram pautas centrais no discurso do campo político da esquerda, além de levar tais pautas a sua atuação política, certamente contribuiu para que ela se tornasse um símbolo, e isso certamente nos ajuda a responder aos questionamentos centrais do trabalho. No entanto, acreditamos que a análise discursiva aqui operada nos permite conferir maior grau de profundidade a essa questão.

Num primeiro momento, fica claro que a campanha desinformativa contra Marielle Franco após a sua morte não tinha uma clara função pragmática imediata, uma vez que ela, à época, não era um nome majoritário na política brasileira, e não havia necessidade de convencer as pessoas a não votarem nela. Podemos, então, listar algumas funções discursivas da campanha de desinformação. A primeira é mais óbvia: num cenário de política hiperpolarizada, às vésperas de uma eleição presidencial, a morte de Marielle a tornou um símbolo do que é percebido, no Brasil contemporâneo, como valores e pautas de esquerda. Podemos, então, afirmar que o cenário político transformou a ex-vereadora numa metonímia da própria esquerda. Ela se tornou a parte pelo todo. Atacar a imagem de Marielle significaria, então, atacar a própria esquerda.

Ainda que as pautas identitárias tenham motivado ataques do campo político rival à imagem de Marielle, nossa análise mostrou que elas não foram o elemento central no discurso das campanhas desinformativas. Recuperando o estudo de Gallego et al. (2017), os militantes de direita parecem ter posturas menos homogêneas em relação a questões de gênero e sexualidade. 0 que, de fato, une os diferentes indivíduos nesse campo é, além do antipetismo e do discurso meritocrático, o discurso punitivo, que defende penas mais rígidas para criminosos, redução da maioridade penal, entre outras demandas. 0 discurso do conservadorismo punitivo, como vimos, está ancorado em esquemas binários maniqueístas, que dividem o mundo entre "cidadãos de bem" e "criminosos", e que despreza os direitos humanos como direitos de bandidos. Nesse esquema, os policiais assumem um papel central de heróis que lutam contra o mal. 
Marielle Franco, ao complexificar o debate sobre segurança pública e questionar o abuso e a violência policial nas favelas cariocas, tensionava o esquema discursivo do conservadorismo punitivo. Isso ganha ainda mais relevância se observarmos que o tema da segurança pública foi o mais abordado pela ex-vereadora em seus pronunciamentos oficiais na Câmara Municipal. 0 assassinato de Marielle, por sua vez, ameaçou a coerência ideológica da FD do conservadorismo punitivo. Os elementos textuais das fake news analisadas foram pensados para "adequar" os fatos ao mundo idílico maniqueísta criado pela FD do conservadorismo punitivo. Marielle não poderia ter sido assassinada por policiais ou ex-policiais, já que eles são os heróis da história. Então, seu assassinato teria que ser contado a partir de uma narrativa alternativa, em que seu "envolvimento com bandidos" teria provocado sua morte. Essa foi a linha central da campanha desinformativa e difamatória contra Marielle após a sua morte, ainda que elementos discursivos raciais e de gênero tenham sido usados para auxiliar no processo de inserção de Marielle no campo "mal" do código binário da FD do conservadorismo punitivo. A campanha desinformativa teve, então, a função de manter o amálgama que conecta o grupo através da manutenção da coerência discursiva.

\section{Referências bibliográficas}

ABRANCHES, Sérgio. Polarização radicalizada e ruptura eleitoral. In: Democracia em risco? 22 ensaios sobre o Brasil hoje. São Paulo: Companhia das Letras, 2019, p. 11-34.

ALONSO, Angela. A comunidade moral bolsonarista. In: Democracia em risco? Ensaios sobre o Brasil hoje. São Paulo, SP: Companhia das Letras, 2019, p. 52-70.

BAKIR, Vian; MCSTAY, Andrew. Fake news and the economy of emotions: problems, causes, solutions. Digital Journalism, v. 6, n. 2, p. 154-175, 2017. Disponível em: https://www.tandfonline.com/doi/abs/10.1080/21670811.2017.1345645. 
CERQUEIRA, Daniel et al. Atlas da violência 2019. Ipea, 2019. Disponível em: http://www.ipea.gov.br/portal/index.php?option=com content\&id=34784\&Itemid=432. Acesso em 20/08/2020.

CÔRTES, Giovana Xavier da C. Coisas de pele: relações de gênero, literatura, e mestiçagem feminina (Rio de Janeiro, 1880-1910). 2005. Dissertação (Mestrado em História). Niterói, Universidade Federal Fluminense, Rio de Janeiro.

EADY, Gregory; NAGLER, Jonathan; GUESS, Andy; ZILINSKY, Jan; TUCKER, Joshua A. How Many People Live in Political Bubbles on Social Media? Evidence From Linked Survey and Twitter Data. SAGE Open, 2019, p. 1-21. Disponível em: https://journals.sagepub.com/doi/pdf/10.1177/2158244019832705.

EL-BERMAWY, Mostafa. Your fillter bubble is destroying democracy. Wired, 2016. Disponível em: https://www. wired.com/2016/11/!lter-bubble destroying-democracy/. Acesso em 20/08/2020.

FOUCAULT, Michel. L'arquéologie du savoir. Paris: Éditions Gallimard, 1969.

FOUCAULT, Michel. L'ordre du discours. Paris: Éditions Gallimard, 1971.

GALLEGO, Esther, ORTELLADO, Pablo, \& RIBEIRO, Márcio. Guerras culturais e populismo anti-petista nas manifestações de apoio a Lava Jato e contra a reforma da previdência. Debate, vol. 9, n. 2, 2017, p. 35-45. Disponível em:

<https://bdpi.usp.br/item/002854247>.

BERGER, Guy. Foreword. In: IRETON, Cherilyn; POSETTI, Julie (orgs). Journalism, Fake News \& Disinformation: Handbook for Journalism Education and Training. Paris: UNESCO, 2018.

IYENGAR, Shanto; LELKES, Yphtach; LEVENDUSKY, Matthew; MA LHOTRA, Neil; WESTWOOD, Sean J. The Origins and Consequences of Affective Polariz ation in the United States. Annual Review of Political Science, v. 22, n. 1, 2019. p. 129-146. Disponível em: https://www.annualreviews.org/doi/abs/10.1146/annurev-polisci-051117-073034.

LEE, Timothy. B. How social media creates angry, poorly informed partisans. Vox, 2016. Disponível em: https://www.vox.com/policy-andpolitics/2016/10/26/13413292/socialmedia-disrupting-politics. Acesso em 02/05/2020. 
LEMOS, André. Nova esfera conversacional. In KUNSCH, et al. (orgs.). Esfera pública, redes e jornalismo. Rio de Janeiro: E-papers, 2009, p. 9-30.

MAINGUENEAU, Dominique. Formação discursiva, unidades tópicas e não-tópicas. In BARONAS, Roberto (org.). Análise do Discurso: Apontamentos para uma história da noção conceito de formação discursiva. São Carlos: Pedro \& João Editores. 2011, p. 63-91.

MAINGUENEAU, Dominique. Gênese dos Discursos. São Paulo: Parábola Editorial, 2008. MASON, Liliana. Uncivil Agreement: How Politics Became Our Identity. Chicago: University of Chicago Press, 2018.

MCINTYRE, Lee. Post-Truth. Cambridge: MIT Press, 2018. E-book Kindle.

MENDONÇA, Heloisa, MARREIRO, Flávia. "MBL e deputado propagam mentiras contra Marielle Franco em campanha difamatória". El País Brasil, 2018. Disponível em: https://brasil.elpais.com/brasil/2018/03/17/politica/1521318452_688519.html.

MONITOR DO DEBATE POLÍTICO NO MEIO DIGITAL. Difusão dos boatos sobre Marielle Franco. 2018. Observatório da Imprensa. Disponível em: http://www.observatoriodaimprensa.com.br/monitor-do-debate-politico-do-meiodigital/difusao-dos-boatos-sobre-marielle-franco/.

ORTELLADO, Pablo; RIBEIRO, Márcio. Polarização e desinformação online no Brasil.Friedrich-Ebert-Stiftung, Análise, n. 44/2018. Disponível em: https://library.fes.de/pdf-files/bueros/brasilien/14629.pdf. Acesso em 20/03/2020.

PARISIER, Eli. The Filter Bubble. New York: The Penguin Press, 2011.

RECUERO, Raquel; ZAGO, Gabriella; SOARES, Felipe. Mídia Social e Filtros-Bolha nas Conversações Políticas no Twitter. Anais do XXVI Encontro Anual da Compós. São Paulo: Compós, 2017. Disponível em: https://lume.ufrgs.br/handle/10183/166193. Acesso em 20/03/2020.

SOUZA, Fabiana. Os manos não são humanos direitos? Anais do VIII Seminário de Estudos em Análise do Discurso. Recife: SEAD, 2017. Disponível em: https://www.discursosead.com.br/posteres-viii-sead. Acesso em 20/03/2020.

WARDLE, Claire.; DERAKHSHAN, Hossein. Information disorder: Toward an interdisciplinary framework for research and policy making. Report. Strasbourg: Council 
of Europe, 2017. Disponível em: https://tverezo.info/wpcontent/uploads/2017/11/PREMS-162317-GBR-2018-Report-desinformation-A4BAT.pdf. Acesso em 17/09/2019.

Dossiê Guerras Culturais - https://revistaecopos.eco.ufri.br/

ISSN 2175-8689 -v. 23, n. 3, 2020

DOI: 10.29146/ecopos.v24i2.27694 